\title{
Consistency between GRUAN sondes, LBLRTM and IASI
}

\author{
Xavier Calbet $^{1}$, Niobe Peinado-Galan ${ }^{2}$, Pilar Rípodas $^{1}$, Tim Trent ${ }^{3,4}$, Ruud Dirksen ${ }^{5}$, and Michael Sommer \\ ${ }^{1}$ AEMET, C/Leonardo Prieto Castro, 8, Ciudad Universitaria, 28071 Madrid, Spain \\ ${ }^{2}$ University of Valencia, Physics Faculty, Carrer del Dr. Moliner, 50, 46100 Burjassot, Valencia, Spain \\ ${ }^{3}$ Earth Observation Science, Department of Physics and Astronomy, University of Leicester, University Road, \\ Leicester, LE1 7RH, UK \\ ${ }^{4}$ National Centre for Earth Observation, Department of Physics and Astronomy, University of Leicester, University Road, \\ Leicester, LE1 7RH, UK \\ ${ }^{5}$ Deutscher Wetterdienst, Meteorologisches Observatorium Lindenberg, Richard-Aßmann-Observatorium, \\ Am Observatorium 12, 15848 Lindenberg/Tauche, Germany
}

Correspondence to: Xavier Calbet (xcalbet@googlemail.com)

Received: 13 October 2016 - Discussion started: 3 November 2016

Revised: 7 April 2017 - Accepted: 10 May 2017 - Published: 27 June 2017

\begin{abstract}
Radiosonde soundings from the GCOS Reference Upper-Air Network (GRUAN) data record are shown to be consistent with Infrared Atmospheric Sounding Instrument (IASI)-measured radiances via LBLRTM (Line-By-Line Radiative Transfer Model) in the part of the spectrum that is mostly affected by water vapour absorption in the upper troposphere (from $700 \mathrm{hPa}$ up). This result is key for climate data records, since GRUAN, IASI and LBLRTM constitute reference measurements or a reference radiative transfer model in each of their fields. This is specially the case for night-time radiosonde measurements. Although the sample size is small (16 cases), daytime GRUAN radiosonde measurements seem to have a small dry bias of $2.5 \%$ in absolute terms of relative humidity, located mainly in the upper troposphere, with respect to LBLRTM and IASI. Full metrological closure is not yet possible and will not be until collocation uncertainties are better characterized and a full uncertainty covariance matrix is clarified for GRUAN.
\end{abstract}

\section{Introduction}

Temperature and water vapour are two of the essential climate variables (ECVs) from Global Climate Observing System (GCOS). The ECVs are variables that are required to support the work of the United Nations Framework Convention on Climate Change (UNFCC) and the Intergovernmental Panel on Climate Change (IPCC) and that are technically and economically feasible for systematic observation. The required performance for satellite-based upper-air temperature and water vapour data products for climate from GCOS are very demanding (WMO GCOS, 2011). A summary of the requirements for atmospheric water vapour is shown in Table 1.

Temperature and water vapour are ECVs for which satellite observations can make a significant contribution - in particular from operational meteorological satellites by means of (passive) top-of-atmosphere (TOA) radiance measurements. Observations from space have several advantages, in particular (i) spatial coverage, which can be global, and (ii) continuous sampling of the atmosphere at regular intervals. Their main disadvantage is that they do not directly observe the Earth system but rather indirectly sense it by measuring the radiance from the Earth impinging on the satellite instrument. To measure the ECVs, it is necessary to convert measured radiances into atmospheric temperature and water vapour profiles. This is usually accomplished by modelling the pathways of radiation in the atmosphere via radiative transfer models (RTMs). The inverse process allows for profiles of temperature and water vapour to be retrieved from the satellite-measured radiances. The inversion can be performed either as a straightforward inversion or, in the case of numerical weather prediction (NWP), by assimilating radiances into short- and medium-range forecasting models. The retrieval or assimilation method may contain inaccuracies either due to one or more of the following: (i) imperfect mod- 
Table 1. GCOS target requirements for the satellite-based essential climate variable (ECV) of water vapour (WMO GCOS, 2011).

\begin{tabular}{llllll}
\hline $\begin{array}{l}\text { Variable/ } \\
\text { parameter }\end{array}$ & $\begin{array}{l}\text { Horizontal } \\
\text { resolution }\end{array}$ & $\begin{array}{l}\text { Vertical } \\
\text { resolution }\end{array}$ & $\begin{array}{l}\text { Temporal } \\
\text { resolution }\end{array}$ & Accuracy & Stability \\
\hline Total column water vapour & $25 \mathrm{~km}$ & $\mathrm{n} / \mathrm{a}$ & $4 \mathrm{~h}$ & $2 \%$ & $0.3 \%$ \\
\hline $\begin{array}{l}\text { Tropospheric and lower- } \\
\text { stratospheric profiles of } \\
\text { water vapour }\end{array}$ & $\begin{array}{l}25 \mathrm{~km} \\
\text { (troposphere) } \\
100-200 \mathrm{~km} \\
(\text { stratosphere) }\end{array}$ & $2 \mathrm{~km}$ & $\begin{array}{l}\text { (troposphere) } \\
\text { Daily } \\
\text { (stratosphere) }\end{array}$ & $5 \%$ & $0.3 \%$ \\
\hline Upper-tropospheric humidity & $25 \mathrm{~km}$ & $\mathrm{n} / \mathrm{a}$ & $1 \mathrm{~h}$ & $5 \%$ & $0.3 \%$ \\
\hline
\end{tabular}

$\mathrm{n} / \mathrm{a}=$ not applicable

elling of the atmosphere, (ii) auxiliary data used or (iii) inaccuracies inherent to the assumptions made by the technique itself, such as Gaussian uncertainty distribution assumptions, trace gases concentrations or others.

Whether radiances or temperature and water vapour profiles are measured, for them to be useful for climate or many other application, they need to be adequately calibrated. The science of metrology defines best practices to achieve this goal. One key element in calibrating is traceability, by which various measurements can be compared. Metrological traceability is a property of a measurement result whereby the result can be related to a reference through a documented unbroken chain of calibrations, each contributing to the measurement uncertainty. In simple terms metrological traceability is a direct link between the result of a measurement made in the field and the result of the best possible measurement made in a calibration laboratory. It ensures that different measurement methods and instruments used at different locations and at different times produce reliable, repeatable, reproducible, compatible and comparable measurement results. When a measurement result is metrologically traceable, it can be confidently linked to the internationally accepted measurement references. Traceability of metrological measurement results are assured by ensuring a documented, unbroken chain of instrument calibrations, from the operational instruments used for field measurements all the way up the metrological hierarchy pyramid to the primary standard. At the top of the pyramid is an internationally defined and accepted reference, in most cases the International System of Units (SI), whose technical and organizational infrastructure has been developed by the Bureau International des Poids et Mesures - BIPM (www.bipm.org).

For the case described here, the measurement process consists of three fundamental elements: (i) the radiance measurement from the satellite instrument, (ii) the temperature and water vapour measurements from the radiosondes and (iii) the RTM that establishes the link between them. Throughout this measurement process, not all elements in the traceability chain are usually used comprehensively. In operational meteorological satellites, instruments are usually calibrated against well-defined standards on the ground before launch. It is often the case that these instruments, and particularly their components, have critical properties which vary with time, degrading once the satellite is in space - effectively breaking the full traceability chain. RTM simulations of the observed TOA radiances usually do not propagate uncertainties arising from gaps in knowledge about the spectroscopy, therefore breaking again the traceability chain. Radiosonde measurements provided by the GCOS Reference Upper-Air Network (GRUAN) adhere to metrology best practices as they provide an accurate estimation of all uncertainties involved in the measurements (Dirksen et al., 2014).

With the goal of achieving an unbreakable chain of calibrations in the future, the satellite community is establishing a set of standards to which all other measurements can use as reference. The objective is to ultimately have these references calibrated through an unbroken traceability chain to primary standards. These current standards are described in the following:

- The Global Space-based Inter-Calibration System (GSICS) is an international collaborative effort initiated in 2005 by the World Meteorological Organzation (WMO) and Coordination Group for Meteorological Satellites (CGMS) to monitor, improve and harmonize the quality of observations from operational weather and environmental satellites of the Global Observing System (GOS). GSICS aims at ensuring consistent accuracy among space-based observations worldwide for climate monitoring, weather forecasting and environmental applications. For infrared (IR) sensors, the standard instrument being adopted by GSICS is the Infrared Atmospheric Sounding Instrument (IASI) (GSICS, 2014; Hewison et al., 2013).

- For radiative transfer models the satellite community working with IR sensors commonly uses line-by-line radiative transfer models. They make use of laboratory measurements of gas absorption spectra to perform their calculations, simulating the radiative transfer that occurs in the real atmosphere. One of such de facto stan- 
dards is LBLRTM (Line-By-Line Radiative Transfer Model), which is the one tested in this paper (Clough et al., 2005).

- The GRUAN community takes great care to keep the chain of traceability unbroken (e.g. Dirksen et al., 2014). The sonde data are provided by GRUAN, removing, as far as possible, all the systematic errors in the measurements and quantifying very well the uncertainty in the measurements (WMO GCOS, 2013b).

When transforming IR measured radiances into atmospheric parameters - effectively performing what are known as retrievals, or as a component of data assimilation, where radiances are used to improve the original atmospheric profile estimation from NWP - it is necessary to keep the chain of traceability between all its elements unbroken. A first step into this direction is checking that all these elements are effectively consistent. That is, the consistency between IASI measurements, GRUAN sondes and LBLRTM calculations is a necessary condition to have an adequate chain of traceability. The consistency of all these components, with the elements available today, is the main subject of this paper.

Comparisons of measurements are usually done in temperature and humidity profile space, where a retrieval is compared to a radiosonde measurement (e.g. Tobin et al., 2006; Reale et al., 2012). Despite being a legitimate comparison, this practice is not the best option when consistency is pursued. Retrieving a profile from a radiance spectrum is an illposed problem which leads to solutions that are not unique. In other words, very different atmospheric profiles can lead to the same radiances measured at the top of the atmosphere. It is therefore a much more robust process to perform the comparisons in radiance space, where the problem is uniquely determined (e.g. Calbet et al., 2011). This is the practice followed in this paper. It is worth noting that there are two main disadvantages in using this technique. One is that an RTM to calculate the GRUAN-derived radiances is needed for this exercise. This is not always the case when performing retrievals, in particular regression retrievals based on real data (e.g. Blackwell, 2005). The second one is that currently RTMs are precise and straightforward to use only in clearsky cases, and therefore the consistency study can only be practically done in clear-sky scenes.

\section{Consistency}

In order for different components to be consistent, their measurements need to lie (on average) between their uncertainties. This is described by the Immler at el. (2010) equation

$\left|m_{1}-m_{2}\right|<k \sqrt{\sigma^{2}+u_{1}^{2}+u_{2}^{2}}$

where $m_{1}$ and $u_{1}$, and $m_{2}$ and $u_{2}$ are the measurements and uncertainties from instrument 1 and 2 respectively. The term $\sigma$ is the uncertainty inherent in the particular comparison that is being performed. For the case of comparing IASI and GRUAN radiosonde data, the biggest component in this $\sigma$ term is usually the collocation uncertainty but can also include uncertainties in the RTM. The $k$ parameter is a value that estimates the ratio between both sides of the inequation. For the measurements to be consistent, this $k$ value has to be around 2 (Immler at el., 2010). If the measurement differences lie within their associated uncertainties (i.e. $\sqrt{u_{1}^{2}+u_{2}^{2}}$ ), then the collocation uncertainty can be assumed to be small. This is the ideal situation when validating IASI retrievals with radiosondes (Calbet, 2016). If, on the other hand, the $\sigma$ term is not negligible, then the measurement difference should follow the complete Eq. (1). The measurement sample used in this paper falls in the latter case, and it will be necessary to use Eq. (1) fully. Moreover, as we shall see, it will not be possible to fully estimate all the quantities in this inequation, preventing a full metrological closure. Nevertheless, some consistency can still be verified, and useful conclusions can be drawn.

The different components that are verified in this paper to be consistent are described in the following subsections.

\subsection{IASI}

Space-borne IR hyperspectral instruments typically measure Earth views in a spectral range from 600 to $3000 \mathrm{~cm}^{-1}$ wave numbers with a spectral sampling of about $0.25 \mathrm{~cm}^{-1}$ providing thousands of channels across their full spectral range. The typical noise per channel of these instruments is roughly in the range from 0.1 to $0.8 \mathrm{~K}$ as noise-equivalent delta temperature at $280 \mathrm{~K}$. From these measurements, it is possible to retrieve atmospheric profiles of temperature and water vapour with a relatively high vertical resolution and high degree of accuracy. These so-called retrievals can have a temperature accuracy of about $1 \mathrm{~K}$ in layers $1 \mathrm{~km}$ thick and humidity accuracy from 10 to $20 \%$ in layers $2 \mathrm{~km}$ thick within the troposphere (Smith Sr. et al., 2001). One such IR hyperspectral instrument is IASI, described by Chalon et al. (2001) and Blumstein et al. (2004). It is a Fourier transform spectrometer currently on board the polar-orbiting satellites Metop-A and Metop-B. IASI is measuring within the whole spectral range from 645 to $2760 \mathrm{~cm}^{-1}$ with a spectral sampling of $0.25 \mathrm{~cm}^{-1}$, at an apodized effective resolution of $0.5 \mathrm{~cm}^{-1}$ and with a spatial resolution of about $12 \mathrm{~km}$ at nadir. Its overall measurement uncertainty has been determined by CNES (Centre National d'Études Spatiales), which has derived the IASI covariance matrix instrument measurement uncertainty (Pequignot et al., 2008).

IASI has been compared with various calibration references, both pre-flight and in orbit. However, reference values with associated uncertainties that are traceable to SI standards have not been assigned. Moreover, while in orbit the instrument has no SI source, and hence the traceability to 
an SI standard once the satellite is launched is lost. Despite this, due to its quality and long-term radiometric stability, the GSICS community has declared IASI as a standard to which all other IR satellite sensors can reference (Hewison et al., 2013).

\subsection{LBLRTM}

Spectra at the top of the atmosphere were generated using the reference Line-By-Line Radiative Transfer Model (Clough et al., 2005). LBLRTM has a long development history, and for the current study one of the latest versions (12.2) was adopted. LBLRTM is a versatile, highly accurate radiation code which describes the interaction between matter and radiation at a single wave number. Its spectral resolution for this particular application lies between 0.00025 and $0.0005 \mathrm{~cm}^{-1}$. The accuracy of LBLRTM has been demonstrated in several publications (e.g. Tjemkes et al., 2003). LBLRTM is considered as a standard by the IR RTM community.

\subsection{GRUAN}

GCOS has established and is continuing to develop a reference network for upper-air climate observations (GRUAN). GCOS is a joint undertaking of the WMO, the Intergovernmental Oceanographic Commission (IOC) of the United Nations Educational Scientific and Cultural Organization (UNESCO), the United Nations Environment Programme (UNEP) and the International Council for Science (ICSU). Its goal is to provide comprehensive information on the total climate system, involving a multidisciplinary range of physical, chemical and biological properties, and atmospheric, oceanic, hydrological, cryospheric and terrestrial processes.

GRUAN is a ground-based network for reference observations of upper-air climate parameters. GRUAN is expected to provide long-term, highly accurate measurements of atmospheric profiles, complemented by ground-based state-ofthe-art instrumentation to constrain and calibrate data from more spatially comprehensive global observing systems (including satellites and current radiosonde networks). Two of GRUAN's primary goals are to fully characterize the properties of the atmospheric column and their changes. GRUAN is envisaged as a network of 30-40 high-quality, long-term upper-air observing stations, building on existing observational networks.

The data that are currently certified as meeting the GRUAN standards are the Vaisala RS92 radiosonde data, which are the data that will be used in this paper. The specific GRUAN data used in this paper are the "RS92 GRUAN Data Product Version 2", which has the "RS92-GDP.2" key (Sommer et al., 2012). The GRUAN data processing for the RS92 radiosonde was developed to meet the criteria as a reference measurement (Dirksen et al., 2014). These criteria stipulate the collection of metadata, the use of well-documented cor- rection algorithms and estimates of the measurement uncertainty. An important and novel aspect of the GRUAN processing is that the uncertainty estimates (random and systematic components) are vertically resolved.

\section{Methodology}

\subsection{Data selection}

In order to verify the consistency of all the elements involved in the comparison, ideally a collocation uncertainty close to 0 is desired ( $\sigma \approx 0$, Eq. 1). Pougatchev et al. (2009) studied the variability of temperature and water vapour with radiosondes launched from Lindenberg, reaching the conclusion that to minimize the collocation uncertainty a spatial and temporal window of $25 \mathrm{~km}$ and $30 \mathrm{~min}$ respectively is needed. These collocation criteria are derived from a particular station on the globe, and it might not be possible to extrapolate it to other regions, in particular, to the tropical western Pacific region in which Manus is located, which, as we shall see, is the station selected for this study. Nevertheless, these figures can be taken as a first approximation. During the development of this study it was noted that for water vapour these criteria in reality seem to be too relaxed. Therefore, even stricter criteria or an accurate estimation of the collocation uncertainty are needed (see Sects. 4 and 5 for a discussion on this).

The IASI instrument flies on board Metop which is in a mid-morning orbit, overpassing the Equator at around 09:00 h local solar time. Since the GRUAN radiosondes are mostly launched at synoptic times (00:00 Z and 12:00 Z), the locations on the globe where IASI and the GRUAN radiosondes would coincide are located over the middle of the Atlantic or the western Pacific (Fig. 1). As a consequence, the only GRUAN station that meets these criteria is the one located on the island of Manus in the tropical western Pacific region. It should be noted that this station has been discontinued and is no longer providing any data to GRUAN. The time interval within which GRUAN data are available for Manus ranges from 2011 to 2013.

Radiative transfer models are in practice accurately characterized for clear-sky cases, making it therefore necessary to select the clear-sky scenes. There are a total of 597 coincident IASI overpasses and GRUAN radiosonde launches over Manus during this period. From these a further selection of clear-sky cases is needed. The cloud flag available in the standard IASI L1c product is used for a first screening, leaving 76 clear-sky cases. To perform the radiation matching between GRUAN-derived and IASI radiances, a perfectly clear sky scene is needed. Since the IASI L1c cloud flag does not have an efficiency of $100 \%$ in detecting clear-sky cases, a further visual screening of the scenes as seen by AVHRR (Advanced Very High Resolution Radiometer) has been performed. This instrument is flown on board the same satellite (Metop) and has the advantage of having a much higher spatial resolu- 


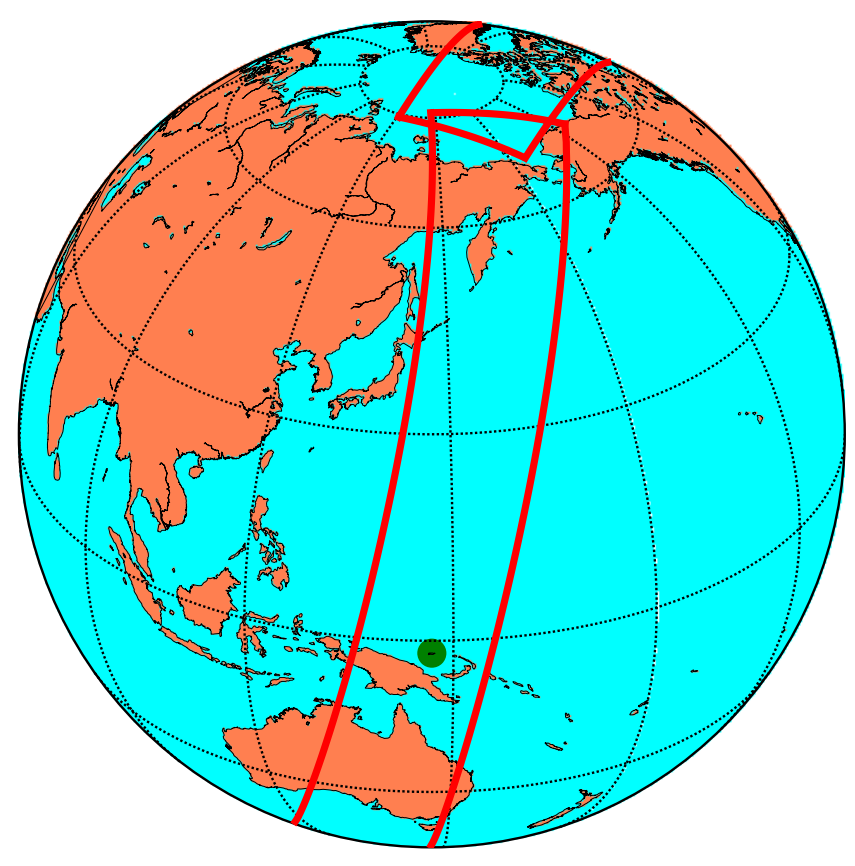

Figure 1. IASI complete orbit (red) on 4 November 2011 at 23:20:57 Z over the observatory location, Manus island (green dot).

tion of around $1 \mathrm{~km}$ at nadir, which makes it specially useful for cloud detection. After this second clear-sky screening is done, only 27 cases are left. These cases are the ones used in the remainder of this paper. All cases with a GRUAN and IASI collocation over Manus, which are clear sky according to the IASI L1c cloud fraction, are listed in Table 2.

\subsection{Further processing of the GRUAN profiles}

According to Calbet et al. (2011) one of the key subjects identified as critical to match IASI radiances to the ones based on RS92 radiosonde data is the radiation dry-bias correction applied to the radiosonde humidity measurements. These corrections are needed in the RS92 data to realistically represent the water vapour present in the atmosphere. The standard processing of the radiosonde data made by GRUAN (Dirksen et al., 2014) corrects for this effect, and no further processing is needed.

The useability of the RS92 humidity profiles is largely determined by the amount of water vapour present. Above the tropopause the water vapour level drops by approximately 2 orders of magnitude. The intrinsic uncertainty of the radiosonde humidity profile is $1 \% \mathrm{RH}$ or more, meaning that at low relative humidity $(\mathrm{RH})$ levels, which typically occur in the stratosphere, the relative uncertainty of the measurement is $100 \%$, which renders the data of little use in the present exercise. In the examples in this paper, humidity measurements from the GRUAN radiosondes are taken as useful when they are physically below $100 \mathrm{hPa}$, which, for these cases, is just below the tropopause. Regarding temperature, the burst of the balloon is what limits their altitude. The GRUAN objective is to aim for a maximum altitude of $5 \mathrm{hPa}$. For thicker balloons, in the range of 600 to $1200 \mathrm{~g}$, the burst of the balloons reaches heights between 10 and $4 \mathrm{hPa}$. For radiosondes launched from Manus they are typically limited to an altitude between 30 and $10 \mathrm{hPa}$ due to the use of thinner balloons. This would then be the limit for temperature measurements of these GRUAN data. Because of these upper limitations on temperature and humidity measurements and in order to be able to apply the radiative transfer to the radiosonde profiles, it is necessary to extend them above this altitude up to the TOA. This is done by complementing them in this upper region with European Centre for Medium-Range Weather Forecasts (ECMWF) fields, by taking the nearest operational analysis to the radiosonde launch location in space and time. In the sample dealt with in this paper, there are no big discontinuities between GRUAN measurements and ECMWF profiles; therefore no further processing at the intersection point has been done.

The RS92 sensor measures the relative humidity of the ambient air, whereas the RTM needs as input the water vapour concentration, typically specific humidity. It is therefore necessary to convert the humidity measurements from relative humidity to specific humidity. To do this, a water vapour saturation curve is needed. The final calculated radiances - especially for channels which are most sensitive to upper-air regions, such as the high troposphere, or which have low water vapour concentrations, such as the ones used in this paper are very much dependent on the type of formulation which is selected (Murphy and Koop, 2005). For consistency reasons, and also considering that the GRUAN community takes the Hyland and Wexler (1983) curve as the one best representing the reality, this is the one used in this paper.

Finally, the radiosonde profiles are smoothed with a mean filter of 100 points in the vertical. The reason for this is that the original radiosonde data exhibit high oscillations and spikes which are either extremely oscillatory or spurious, and it is therefore not recommended to feed these raw data as input to the RTM. It must be considered that, in any case, IASImeasured radiances or retrievals are not sensitive to particularly small scales in the vertical. Figure 2 illustrates the processing performed on the GRUAN profiles before they are fed as input to the RTM.

\subsection{RTM radiance calculations and their uncertainties}

Once the profiles are prepared, they are used as input to LBLRTM. To avoid surface effects in the calculated radiances, only the higher absorptive water vapour channels are used in this study. The channels used range from 1400 to $1900 \mathrm{~cm}^{-1}$, covering practically all atmospheric levels from around $700 \mathrm{hPa}$ and above. The output of LBLRTM are radiances at a very high spectral resolution. These spectra then have to be modified to IASI specifications. To do this, the spectra are smoothed down to IASI spectral resolution using 
Table 2. GRUAN RS92 sondes and IASI collocation cases over Manus, where only the clear-sky cases according to IASI L1c cloud fraction are listed.

\begin{tabular}{|c|c|c|c|c|c|c|c|c|c|c|c|c|c|}
\hline$\#$ & $\begin{array}{l}\text { G } \\
D \\
P\end{array}$ & Date & UTC & $\begin{array}{l}\text { Clear } \\
\text { IASI }\end{array}$ & $\begin{array}{l}\text { Clear } \\
\text { vis- } \\
\text { ual }\end{array}$ & $\begin{array}{l}\text { Day/ } \\
\text { night }\end{array}$ & \# & $\begin{array}{l}G \\
D \\
P\end{array}$ & Date & UTC & $\begin{array}{l}\text { Clear } \\
\text { IASI }\end{array}$ & $\begin{array}{l}\text { Clear } \\
\text { vis- } \\
\text { ual }\end{array}$ & $\begin{array}{l}\text { Day/ } \\
\text { night }\end{array}$ \\
\hline 01 & 2 & 10.01 .2011 & 12:00:00 & Yes & No & Day & 39 & 2 & 24.12 .2012 & 00:00:00 & Yes & No & Night \\
\hline 02 & 2 & 11.01 .2011 & 00:00:00 & Yes & Yes & Night & 40 & 2 & 18.01 .2013 & 00:00:00 & Yes & No & Night \\
\hline 03 & 2 & 21.01 .2011 & 12:00:00 & Yes & No & Day & 41 & 2 & 19.01 .2013 & 00:00:00 & Yes & No & Night \\
\hline 04 & 2 & 24.01 .2011 & 00:00:00 & Yes & No & Night & 42 & 2 & 22.01 .2013 & 00:00:00 & Yes & No & Night \\
\hline 05 & 2 & 28.06 .2011 & 00:00:00 & Yes & Yes & Night & 43 & 2 & 05.03 .2013 & 12:00:00 & Yes & Yes & Day \\
\hline 06 & 2 & 10.07 .2011 & 12:00:00 & Yes & Yes & Day & 44 & 2 & 19.03.2013 & 12:00:00 & Yes & No & Day \\
\hline 07 & 2 & 28.07.2011 & 12:00:00 & Yes & Yes & Day & 45 & 2 & 30.03 .2013 & 00:00:00 & Yes & Yes & Night \\
\hline 08 & 2 & 31.07 .2011 & 00:00:00 & Yes & Yes & Night & 46 & 2 & 21.04 .2013 & 12:00:00 & Yes & No & Day \\
\hline 09 & 2 & 04.09 .2011 & 00:00:00 & Yes & No & Night & 47 & 2 & 22.04 .2013 & 00:00:00 & Yes & No & Night \\
\hline 10 & 2 & 15.10 .2011 & 12:00:00 & Yes & Yes & Day & 48 & 2 & 01.05 .2013 & 12:00:00 & Yes & Yes & Day \\
\hline 11 & 2 & 18.10 .2011 & 00:00:00 & Yes & No & Night & 49 & 2 & 02.05 .2013 & 00:00:00 & Yes & No & Night \\
\hline 12 & 2 & 19.10.2011 & 12:00:00 & Yes & Yes & Day & 50 & 2 & 16.05 .2013 & 12:00:00 & Yes & No & Day \\
\hline 13 & 2 & 26.10 .2011 & 00:00:00 & Yes & Yes & Night & 51 & 2 & 17.05 .2013 & 00:00:00 & Yes & No & Night \\
\hline 14 & 2 & 31.10 .2011 & 00:00:00 & Yes & No & Night & 52 & 2 & 19.05 .2013 & 12:00:00 & Yes & No & Day \\
\hline 15 & 2 & 05.11 .2011 & 00:00:00 & Yes & Yes & Night & 53 & 2 & 20.05 .2013 & 12:00:00 & Yes & No & Day \\
\hline 16 & 2 & 15.11 .2011 & 00:00:00 & Yes & No & Night & 54 & 2 & 24.05 .2013 & 12:00:00 & Yes & No & Day \\
\hline 17 & 2 & 20.11 .2011 & 00:00:00 & Yes & No & Night & 55 & 2 & 25.05 .2013 & 00:00:00 & Yes & Yes & Night \\
\hline 18 & 2 & 18.12.2011 & 00:00:00 & Yes & No & Night & 56 & 2 & 25.05 .2013 & 12:00:00 & Yes & Yes & Day \\
\hline 19 & 2 & 23.12 .2011 & 00:00:00 & Yes & Yes & Night & 57 & 2 & 26.05 .2013 & 00:00:00 & Yes & No & Night \\
\hline 20 & 2 & 29.12.2011 & 00:00:00 & Yes & No & Night & 58 & 2 & 31.05 .2013 & 00:00:00 & Yes & No & Night \\
\hline 21 & 2 & 23.01 .2012 & 12:00:00 & Yes & No & Day & 59 & 2 & 05.06 .2013 & 00:00:00 & Yes & No & Night \\
\hline 22 & 2 & 27.01.2012 & 00:00:00 & Yes & Yes & Night & 60 & 2 & 26.06 .2013 & 12:00:00 & Yes & No & Day \\
\hline 23 & 2 & 19.02.2012 & 00:00:00 & Yes & No & Night & 61 & 2 & 06.07 .2013 & 00:00:00 & Yes & No & Night \\
\hline 24 & 2 & 13.04 .2012 & 00:00:00 & Yes & Yes & Night & 62 & 2 & 26.07 .2013 & 00:00:00 & Yes & No & Night \\
\hline 25 & 2 & 08.05 .2012 & 00:00:00 & Yes & No & Night & 63 & 2 & 03.08 .2013 & 00:00:00 & Yes & No & Night \\
\hline 26 & 2 & 17.05 .2012 & 00:00:00 & Yes & No & Night & 64 & 2 & 04.08 .2013 & 00:00:00 & Yes & No & Night \\
\hline 27 & 2 & 18.05 .2012 & 00:00:00 & Yes & No & Night & 65 & 2 & 06.08 .2013 & 12:00:00 & Yes & Yes & Day \\
\hline 28 & 2 & 30.06 .2012 & 12:00:00 & Yes & No & Day & 66 & 2 & 17.08.2013 & 00:00:00 & Yes & Yes & Night \\
\hline 29 & 2 & 15.07.2012 & 12:00:00 & Yes & No & Day & 67 & 2 & 09.09.2013 & 12:00:00 & Yes & Yes & Day \\
\hline 30 & 2 & 17.08.2012 & 00:00:00 & Yes & Yes & Night & 68 & 2 & 21.09.2013 & 00:00:00 & Yes & No & Night \\
\hline 31 & 2 & 19.09.2012 & 00:00:00 & Yes & No & Night & 69 & 2 & 23.09 .2013 & 00:00:00 & Yes & No & Night \\
\hline 32 & 2 & 25.09 .2012 & 00:00:00 & Yes & Yes & Night & 70 & 2 & 27.09.2013 & 00:00:00 & Yes & No & Night \\
\hline 33 & 2 & 03.10 .2012 & 00:00:00 & Yes & No & Night & 71 & 2 & 23.10 .2013 & 00:00:00 & Yes & Yes & Night \\
\hline 34 & 2 & 15.10 .2012 & 12:00:00 & Yes & Yes & Day & 72 & 2 & 04.11 .2013 & 00:00:00 & Yes & No & Night \\
\hline 35 & 2 & 18.10 .2012 & 00:00:00 & Yes & No & Night & 73 & 2 & 16.11 .2013 & 00:00:00 & Yes & No & Night \\
\hline 36 & 2 & 02.11 .2012 & 00:00:00 & Yes & No & Night & 74 & 2 & 23.11 .2013 & 00:00:00 & Yes & Yes & Night \\
\hline 37 & 2 & 17.11 .2012 & 00:00:00 & Yes & No & Night & 75 & 2 & 28.11 .2013 & 12:00:00 & Yes & Yes & Day \\
\hline 38 & 2 & 20.12 .2012 & 00:00:00 & Yes & Yes & Night & 76 & 2 & 02.12 .2013 & 00:00:00 & Yes & No & Night \\
\hline
\end{tabular}

the IASI spectral response function (SRF). Finally the calculated spectra are obtained with the complete characteristics of an ideal IASI instrument. Figure 3 shows calculated radiance differences for a particular atmospheric profile.

The radiosonde profile uncertainties provided by GRUAN (Dirksen et al., 2014) are propagated into radiance space to determine whether all measurements are compatible (Eq. 1). The uncertainties provided with the GRUAN measurements are defined on a per-radiosonde level basis, and there are no covariance terms between levels. These covariances are critical in the propagation of the uncertainties from the profile into radiance space. This is physically due to the fact that IASI observes the Earth, viewing all atmospheric levels at the same time.

There are several ways to propagate the uncertainties from atmospheric profile into radiance space. The most straightforward way of propagating uncertainties is by using the parameter derivatives. In this case, the Jacobians of the radiances with respect to the atmospheric profiles from the radiative transfer equations could be multiplied by the atmospheric profile uncertainties to obtain the radiance uncertainties. These Jacobians are usually available as an output of 
$2011 / 11 / 0423: 44: 19$

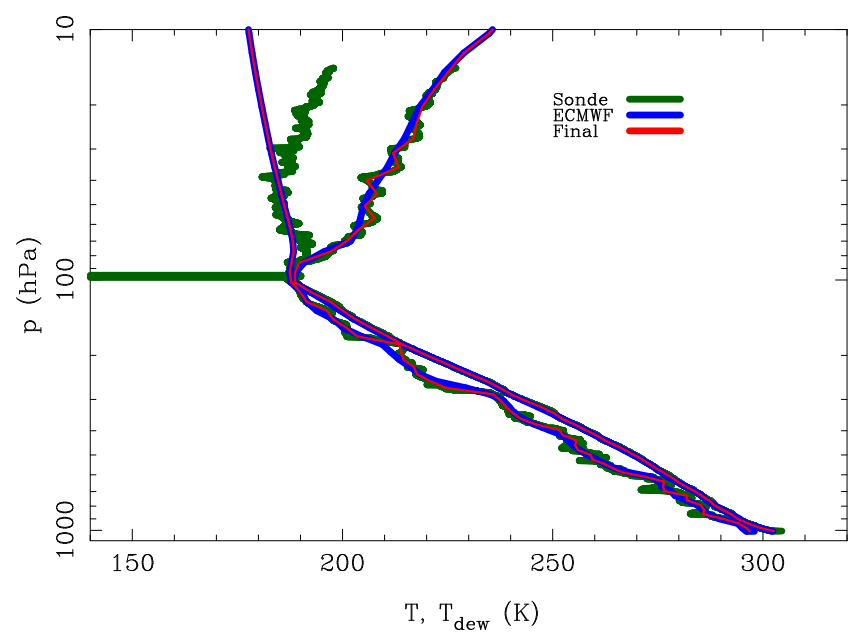

Figure 2. Individual sample of a raw GRUAN sonde (green), the ECMWF profile (blue) and the final profile after pre-processing before being fed as input to LBLRTM (red). The red, green and blue lines to the right show the temperature profiles, while the ones to the left show the humidity profiles represented as dew point temperature.

the RTM. Due to the large number of IASI spectral points and the number of levels in the GRUAN profiles, this method is computationally expensive and impractical for this study. Also, the Jacobian of the radiances is needed, which for the case of LBLRTM can be quite impractical to use and obtain. Added to this, the fact that the uncertainty covariances between levels are not available for GRUAN profiles, it is not evident how to use the Jacobians for this purpose. In this paper, a more practical approach has been taken. The uncertainty propagation has been performed assuming two extreme cases: uncertainty is completely uncorrelated between levels, and there is a perfect correlation between uncertainties from all levels. The truth most likely lies in between these two extremes.

To propagate the uncertainties, assuming no uncertainty correlation between levels, a Monte Carlo method was applied. For each level and variable a random perturbation is added, having a Gaussian distribution with zero bias and a standard deviation equal to the corresponding GRUAN global uncertainty on that level. Each level is perturbed totally independently from the next. After this perturbation is applied, the radiances at the top of the atmosphere are calculated using LBLRTM. This process is repeated several times to obtain the standard deviation of the radiances within the Monte Carlo approach. Since only an estimation of the standard deviation is needed, not too many repetitions are necessary. Eleven have been used in this work, which is a sufficient number for an accurate estimation of the standard deviation. This final standard deviation is taken as the uncertainty of the GRUAN profiles in radiance space. One result for a particu- lar profile is shown in Fig. 5 as an orange curve. It is worth noting that the resulting radiance uncertainty is small compared to the overall IASI instrument uncertainty. The reason for this lies in the lack of any uncertainty correlation between levels which ends up compensating the perturbation in radiance space from one level with the one from another level.

The propagation of uncertainties when assuming a perfect correlation of uncertainties between levels is done by perturbing the temperature and humidity variables by plus or minus the uncertainty as given by GRUAN from that parameter and level consistently over the complete profile. In other words if the temperature is perturbed by plus one GRUAN uncertainty at the surface, the rest of the temperature profile is also perturbed by plus one GRUAN uncertainty for each level. Therefore, there are a total of four different profiles: two coming from the plus and minus addition of one GRUAN uncertainty times another two coming from the two variables, temperature and water vapour. Radiances are then calculated for these four profiles using LBLRTM. To derive a radiance uncertainty from these calculations, all four calculated radiances are subtracted pairwise, giving a total of six differences. Of these six, the greatest difference is taken as the final uncertainty for uncertainty-correlated levels. The combination that provides the greatest uncertainty in this case consisted of plus one GRUAN uncertainty in temperature and minus one GRUAN uncertainty in humidity. Results are shown in Fig. 5 as a dark green curve. Note how this uncertainty is much greater than the previously calculated uncertainty with no uncertainty correlation between levels, as would be expected.

\section{Comparisons}

The differences between calculated radiances obtained from the results of LBLRTM applied to the GRUAN radiosondes and the IASI-measured radiances are computed for the comparison. For illustrative purposes, the calculated radiances obtained from the ECMWF operational analysis profile that is nearest in space and time are also compared to IASI. It is worth recalling that all cases analysed in this paper are clear-sky scenes. Figure 3 illustrates one such sample. The red curve indicates the GRUAN radiosonde calculated radiances compared to IASI. The thickness of this red line indicates the uncertainty in the radiances obtained using the Monte Carlo method and assuming there is no uncertainty correlation between levels. This thickness is so small that is difficult to distinguish in the figure. The blue curve shows the ECMWF profile calculated radiances compared to IASImeasured ones. The black line indicates the overall IASI instrument uncertainty. As we can see for this case, visually, the match is quite remarkable both for GRUAN and ECMWF. Both radiance differences fall overall within the IASI instrument uncertainty (black line). 


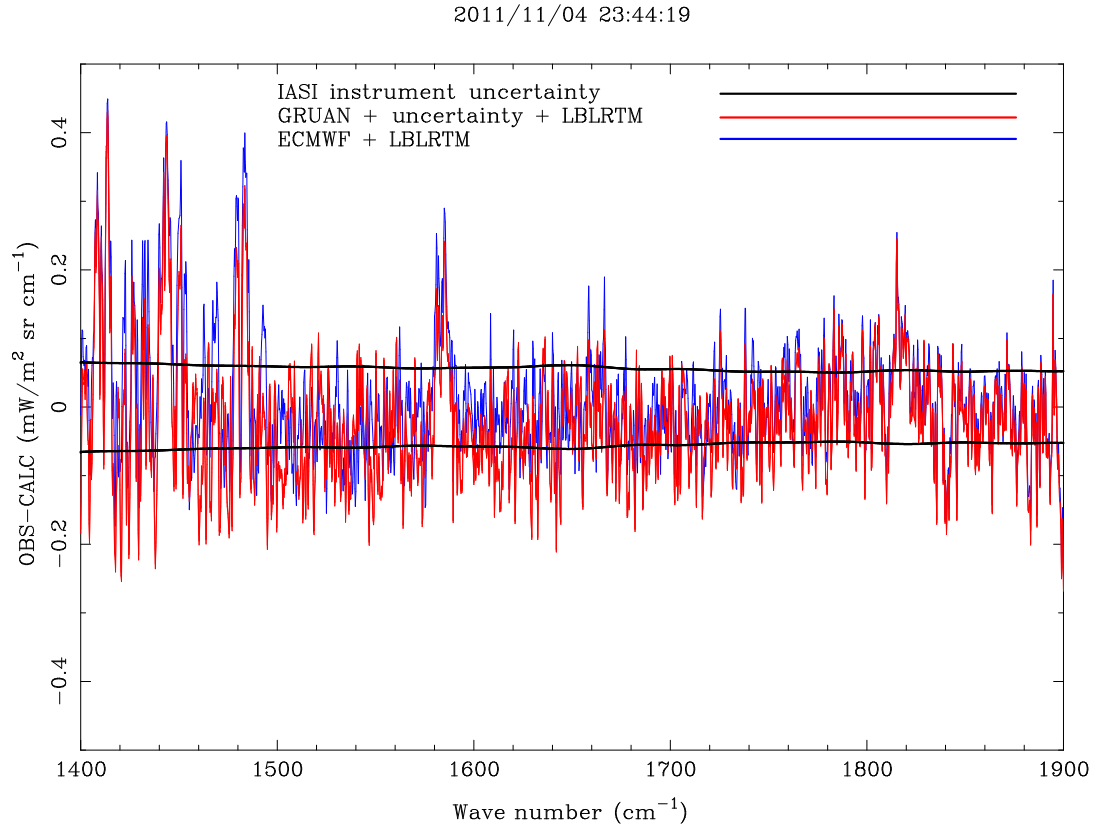

Figure 3. IASI observed minus calculated radiances (OBS-CALC) for a sample sonde (4 November 2011 23:44:19Z). Calculated radiances derived from LBLRTM and GRUAN sondes (red) and ECMWF (blue). IASI overall instrument uncertainty (black). The thickness of the red line (hardly noticeable) denotes the GRUAN uncertainty propagated into radiance space assuming no uncertainty correlation between levels.

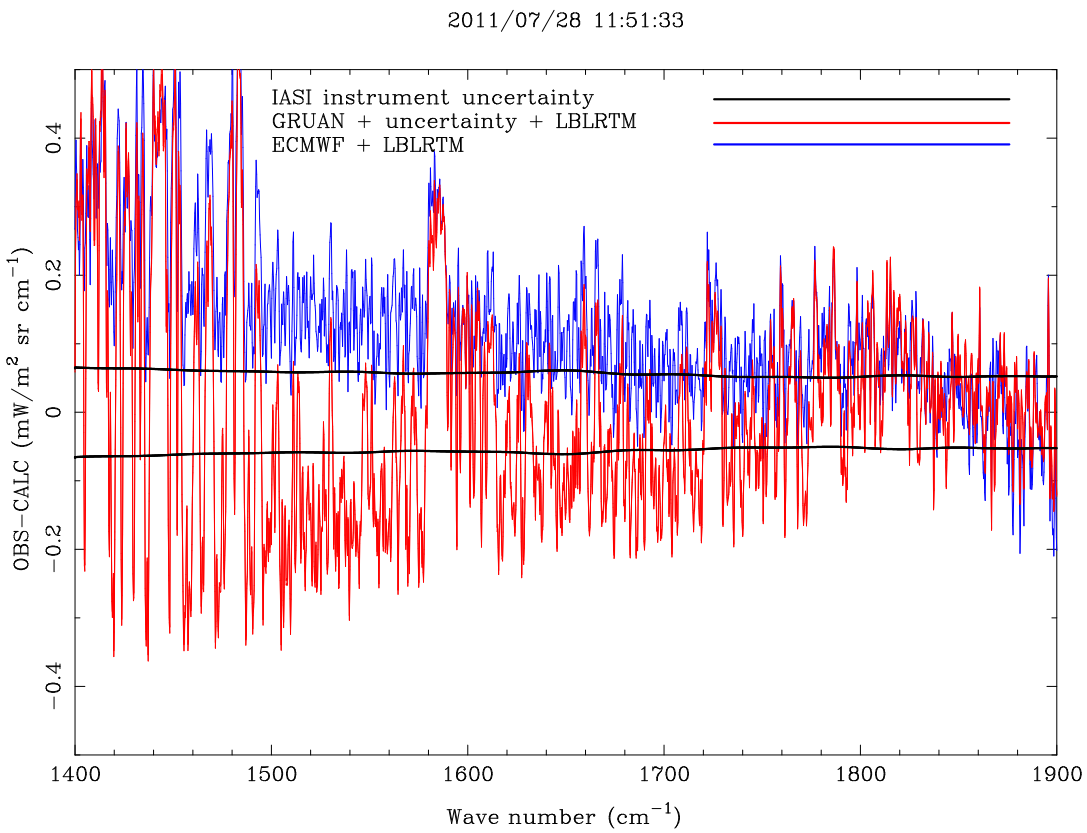

Figure 4. IASI observed minus calculated radiances (OBS-CALC) for a sample sonde (28 July 2011 11:51:33 Z). Calculated radiances derived from LBLRTM and GRUAN sondes (red) and ECMWF (blue). IASI overall instrument uncertainty (black). The thickness of the red line (hardly noticeable) denotes the GRUAN uncertainty propagated into radiance space assuming no uncertainty correlation between levels.

Figure 4 illustrates another sample, again, under a clearsky scene. In this case the match is quite poor. Neither the GRUAN radiosonde nor the ECMWF profile matches the IASI radiances well. We firmly believe that the main cause for this is the extremely high variability of water vapour in the atmosphere, which makes the perfect collocation of GRUAN radiosondes and ECMWF profiles with IASI very difficult. In other words, the $\sigma$ term in Eq. (1) is signifi- 


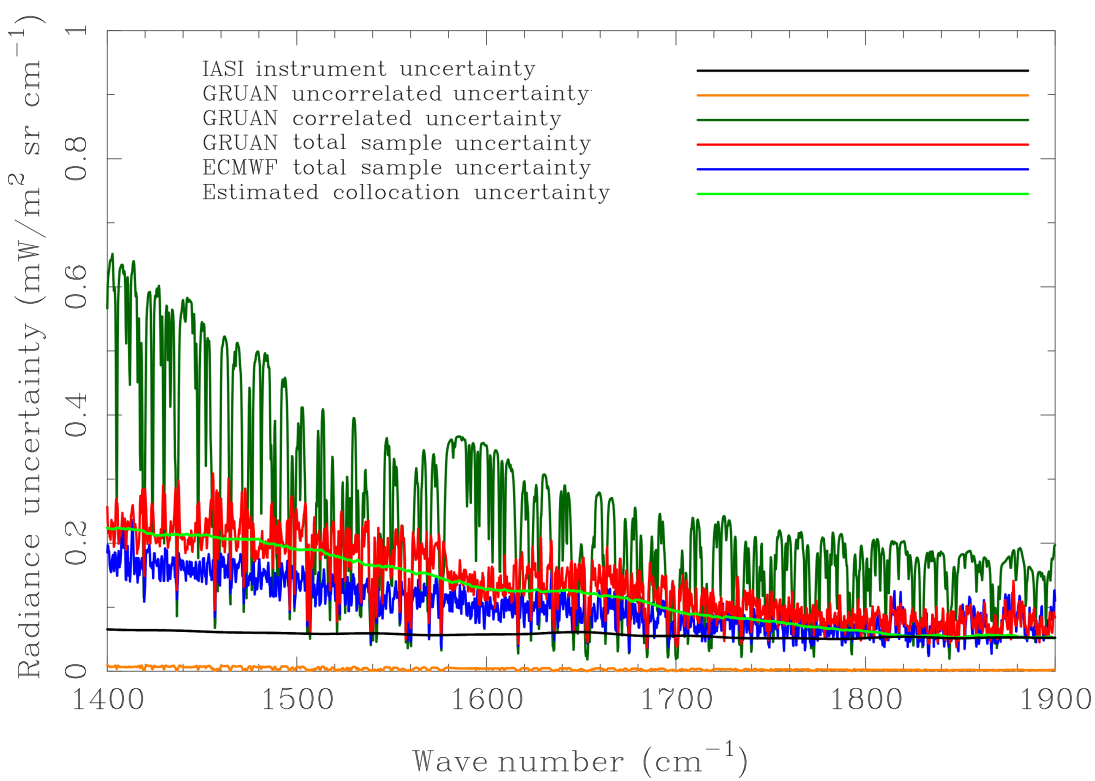

Figure 5. Several radiance uncertainties. IASI overall instrument uncertainty (black); GRUAN instrument uncertainty propagated into radiance space assuming no uncertainty correlation between levels for the 21 January 2011 at 11:41:31 case (orange); GRUAN instrument uncertainty propagated into radiance space assuming perfect uncertainty correlation between levels for the 21 January 2011 at 11:41:31 case (dark green); calculated radiance standard deviation from GRUAN sondes for all the completely clear sky scenes and night-time cases (red); calculated radiance standard deviation from ECMWF profiles for all the clear-sky scenes and night-time cases (blue); estimated collocation uncertainty plus any remaining RTM uncertainties (light green).

cant. Note that this is in contrast with Calbet et al. (2011), where all cases did match individually. The main difference with respect to this study is that in Calbet et al. (2011) dual radiosonde consecutive launches $1 \mathrm{~h}$ apart were available, making a time interpolation possible, whereas, in this paper, the time interpolation is impossible due to only a single radiosonde sounding being available per IASI collocation.

For further reference, note that the standard deviation of the differences for all samples indicates the total uncertainty in the comparison, including collocation, instrument and RTM uncertainties. These are shown in Fig. 5 as a red curve for GRUAN and as a blue curve for ECMWF.

Since the collocation uncertainty is not negligible, all terms from Eq. (1), including $\sigma$, need to be considered. All terms are summarized as follows:

- The IASI instrument uncertainty is available.

- The GRUAN uncertainty in radiance space is only partially available, since the uncertainty correlations between levels is not perfectly known. To have a firm value for the GRUAN uncertainty in radiance space, it will be assumed that there is no uncertainty correlation between GRUAN levels. Illustrating this in Fig. 5, the orange curve will be taken as the GRUAN uncertainty instead of the dark green curve.
- The collocation uncertainty is completely unknown. To overcome this, it will be estimated from the standard deviation of the observed minus calculated radiances from the complete clear-sky and night-time sample. Subtracting from the square of this value, the IASI and GRUAN squared uncertainty, the remaining uncertainties, mostly the collocation uncertainty, squared should be left. Illustrating this in Fig. 5, $\sigma^{2}$ is equal to the square of the red curve minus the square of the black curve minus the square of the orange one. What is left, the collocation uncertainty plus any remaining RTM uncertainties, is shown as a light green curve in the figure. Even though this uncertainty includes all remaining uncertainties, since it is mostly composed of the collocation uncertainty, for brevity, it will be referred to from now on as collocation uncertainty.

Note that by making the assumption of the uncertainty correlation between levels for GRUAN and by calculating the collocation uncertainty from the data themselves, the ideal closure of Eq. (1) will not be achieved. For this to happen, further work is needed on estimating the full GRUAN uncertainty covariance matrices and determining the collocation uncertainty via other means. Nevertheless, as we shall later see, conclusions about the consistency of the data can still be drawn. 


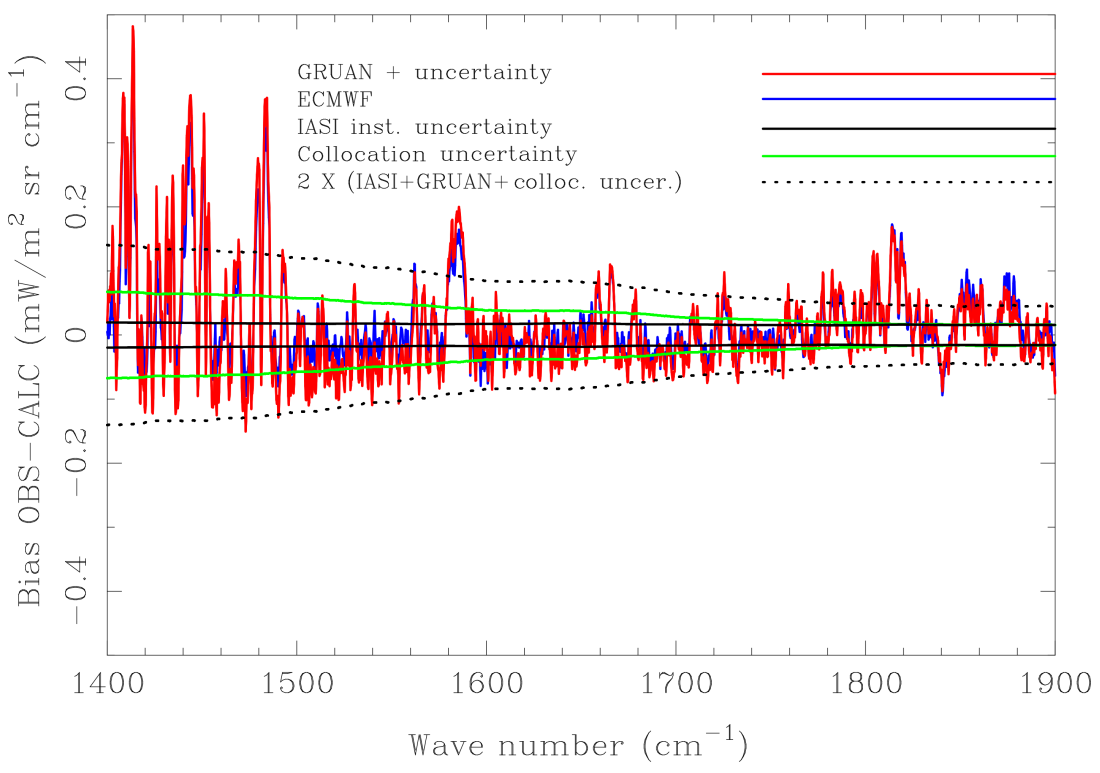

Figure 6. Average radiance difference (bias) between IASI observed and calculated radiances for the completely clear sky scenes and nighttime cases. Calculated radiances are derived from GRUAN sondes (red) and ECMWF profiles (blue). The thickness of the red line (hardly noticeable) denotes the GRUAN uncertainty propagated into bias radiance space assuming no uncertainty correlation between levels. The solid black line shows the IASI instrument uncertainty for this bias. The light green line indicates the collocation uncertainty of this average or bias. The dotted black line indicates 2 times the square root of the squares of the IASI overall instrument plus GRUAN uncertainties plus collocation uncertainties for the bias (the $k \sqrt{u_{1}^{2}+u_{2}^{2}+\sigma^{2}}$ term in Eq. (1) with $k=2$ ).

To minimize the collocation uncertainty, the average of the radiance difference for different cases was calculated. The expectation is that the random perturbations due to collocation uncertainties would average out. For this to happen, these perturbations need to have a normal random distribution. The IASI, GRUAN and collocation uncertainties also need to be re-calculated in order to normalize them with the square root of the size of the averaged sample. Results are shown in Fig. 6 for the night-time cases, where it can be seen that the average difference effectively lies within uncertainty values (black dotted curve). In this figure, the average of the difference between measurements ( $m_{1}$ and $m_{2}$ in Eq. 1) lies within the addition of uncertainties of the measurements $\left(u_{1}\right.$, $u_{2}$ and $\sigma$ in Eq. 1), which are represented in this figure as a solid black line for the IASI instrument uncertainty, as the thickness of the red line for the GRUAN uncertainty (assuming no uncertainty correlation between levels) and as a light green line for the collocation uncertainty. The dotted black line indicates 2 times the composition of all uncertainties, which would be the $k \sqrt{u_{1}^{2}+u_{2}^{2}+\sigma^{2}}$ term in Eq. (1). This is the proof that GRUAN, LBLRTM and IASI are indeed consistent with a $k=2$ from Eq. (1). In the same figure it can also be verified that ECMWF behaves similarly. The few channels that clearly lie outside the overall IASI instrument uncertainty in Fig. 6 are due to the fact that these channels, with wave numbers below $1500 \mathrm{~cm}^{-1}$ and around $1585 \mathrm{~cm}^{-1}$, are affected by surface effects that are not adequately modelled here. For other channels which also lie outside the uncertainty ranges, with wave numbers between 1800 and $1840 \mathrm{~cm}^{-1}$, the reason is unknown.

Figure 7 shows the daytime cases. In this example the coincidence is not satisfactory, lying in some parts of the spectrum outside of the uncertainty tolerances. This is not the case for ECMWF, which does lie well within the uncertainties (like in the night-time cases). This is a clear indication that GRUAN data seem to suffer from a slight bias in the daytime measurements. To quantify this bias, further calculations were made where the relative humidity from the GRUAN radiosondes was artificially incremented by adding $2.5 \%$ in absolute terms of relative humidity. This result is shown in Fig. 8. The match here is reasonable such that these radiances show that GRUAN daytime radiosondes seem to have a dry bias of $2.5 \%$. Although $2.5 \%$ of relative humidity was added to the complete radiosonde profile, the IASI channels that are being analysed here are mostly sensitive to the upper-tropospheric water vapour (from $700 \mathrm{hPa}$ up). Therefore, the bias is mostly coming from these upper layers.

It is interesting to note how the sample size shrinks as we select the data more and more. The initial number of collocations of IASI with GRUAN over Manus during the period this station was operational (2011-2013) was 597 cases. 


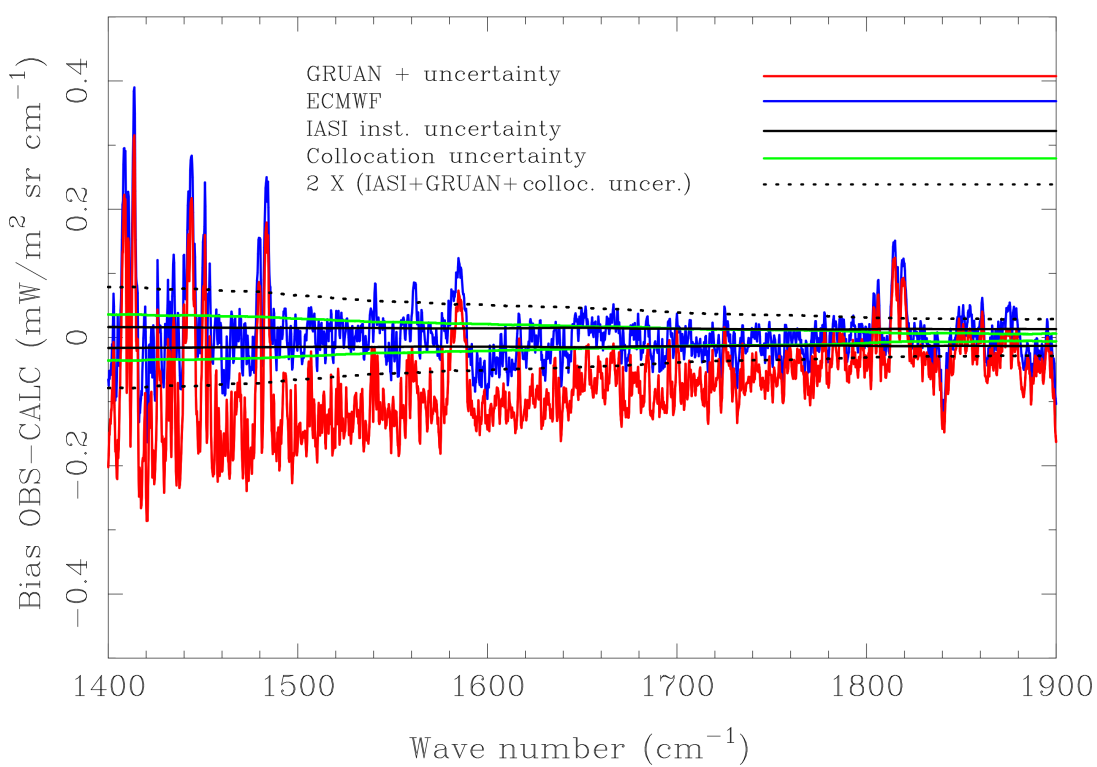

Figure 7. Average radiance difference (bias) between IASI observed and calculated radiances for the completely clear sky scenes and daytime cases. Calculated radiances are derived from GRUAN sondes (red) and ECMWF profiles (blue). The thickness of the red line (hardly noticeable) denotes the GRUAN uncertainty propagated into bias radiance space assuming no uncertainty correlation between levels. The solid black line shows the IASI instrument uncertainty for this bias. The light green line indicates the collocation uncertainty of this average or bias. The dotted black line indicates 2 times the square root of the squares of the IASI overall instrument plus GRUAN uncertainties plus collocation uncertainties for the bias (the $k \sqrt{u_{1}^{2}+u_{2}^{2}+\sigma^{2}}$ term in Eq. (1) with $k=2$ ).

OBS-CALC bias

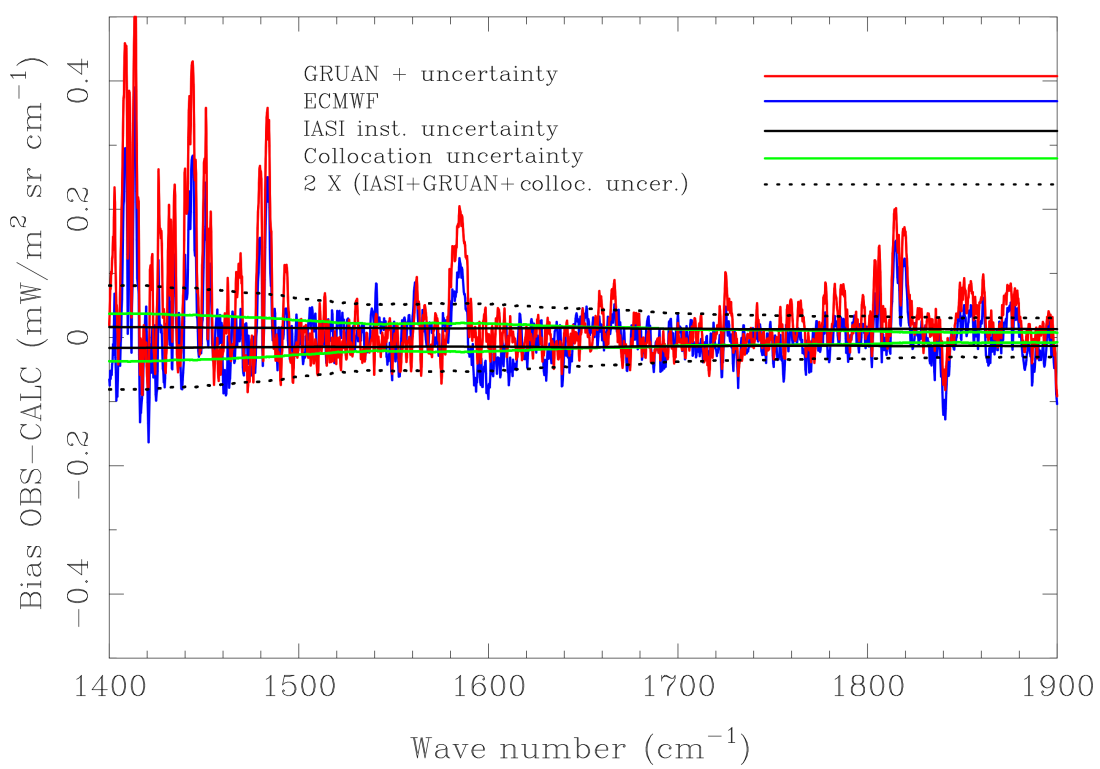

Figure 8. Same as Fig. 7 but artificially adding $2.5 \%$ in absolute terms of relative humidity to the complete GRUAN sonde profile before calculating its radiances. 
Once only clear-sky cases are selected, following the cloud flag present in the IASI L1 product, 76 cases are left. After visual inspection of the scenes, to remove potential residual cloudy cases, only 27 cases remain. Of these, 11 cases are measured during night-time, which are the ones that provide a good match between IASI and GRUAN, and the other 16 daytime cases do not provide a reasonable match-up. This stresses the need for having high-quality radiosonde observations, such as those provided by GRUAN, collocated with satellite overpasses.

\section{Conclusions}

It has been verified that GRUAN, LBLRTM and IASI are indeed consistent with each other, specially for night-time ascents. This is the main result of this paper. This is a key finding when using these measurements in fields where a high accuracy is needed, like climate science. Even though the consistency between GRUAN and IASI cannot be proven on cloudy scenes, it can be expected that GRUAN quality remains unchanged under any conditions, serving its main purpose as a reference network for climate and other applications. Consistency is also necessary for applications such as obtaining accurate retrievals from IASI measurements (Calbet, 2016). It is not straightforward to reach this result, and many critical issues have been identified; these are as follows:

- Adequate collocations are needed. Scale lengths and times of water vapour are extremely small as Carbajal Henken et al. (2015) have clearly demonstrated using MERIS data. This makes it very complicated to obtain perfect match-ups. If a small collocation uncertainty is desired, it is mandatory to use small collocation windows (typically smaller than $25 \mathrm{~km}$ and $30 \mathrm{~min}$ ). Also desirable would be a double radiosonde launch, where both radiosondes are launched separated by approximately $1 \mathrm{~h}$. In this way, a time interpolation known as Tobin interpolation is possible (Tobin et al., 2006). This technique provided match-ups even for individual cases in the past (Calbet et al., 2011). Also, standard deviations of the complete sample were very close to the IASI instrument uncertainty. This result is very clear in Fig. 15 of Calbet et al. (2011), as opposed to the results obtained in this paper with single radiosonde launches (red curve of Fig. 5).

- To achieve a full metrological closure, the full GRUAN uncertainty matrix is needed. This matrix would show the uncertainty correlations between levels and between parameters, temperature and water vapour. To fully characterize the comparison, a method to estimate the collocation uncertainty would be desirable. This method should not depend on the data being used for the study and should be independent from them.
- The water vapour saturation function used to convert from relative humidity measured by the radiosonde to some form of water concentration, such as specific humidity, is highly critical. In this case, following Dirksen et al. (2014), the Hyland and Wexler (1983) water vapour saturation function was used.

- It is also very important to correct the RS92 radiosonde measurements from all potential systematic errors they might have. For this, the GRUAN processing plays a key role, removing such biases and providing the necessary uncertainties to make a meaningful comparison.

- Proper cloud detection is also critical. A few cases with spurious clouds will adversely affect the consistency results. In this paper, an additional visual cloud detection was done on the data with the help of AVHRR images.

- GRUAN processing seems to still have a remaining bias of around $2.5 \%$ in absolute terms of relative humidity for radiosondes flown during daytime, which is corroborated by the fact that this effect does not seem to show up in night-time sondes nor in ECMWF profiles.

- Results from this paper are drawn with very limited sample sizes (11 night-time and 16 daytime), so they should be taken with care. A study with more cases should be performed in the future. The need for more radiosonde launches coincident with satellite overpasses should also be stressed.

- The results shown in this paper would have been impossible with other data of lower quality than GRUAN data. The fact that the GRUAN community strives to provide bias-free data and an uncertainty associated with each measurement is what has made this study possible.

Data availability. GRUAN radiosonde data are available from GRUAN, IASI data are available from EUMETSAT and the LBLRTM model is available from AER.

Competing interests. The authors declare that they have no conflict of interest.

Acknowledgements. We acknowledge the editor Domenico Cimini and the anonymous referees for their helpful comments, which have greatly improved the paper.

Edited by: Domenico Cimini

Reviewed by: three anonymous referees 


\section{References}

Blackwell, W. J.: A neural-network technique for the retrieval of atmospheric temperature and moisture profiles from high spectral resolution sounding data, IEEE T. Geosci. Remote Sens., 43, 2535-2546, 2005.

Blumstein, D., Chalon, G., Carlier, T., Buil, C., Hébert, P., Maciaszek, T., Ponce, G., Phulpin, T., Tournier, B., and Siméoni, D.: IASI instrument technical overview and measured performances, SPIE Conference, Denver (Co), SPIE 2004-5543-22, August 2004.

Calbet, X.: Assessment of adequate quality and collocation of reference measurements with space-borne hyperspectral infrared instruments to validate retrievals of temperature and water vapour, Atmos. Meas. Tech., 9, 1-8, https://doi.org/10.5194/amt-9-12016, 2016.

Calbet, X., Kivi, R., Tjemkes, S., Montagner, F., and Stuhlmann, R.: Matching radiative transfer models and radiosonde data from the EPS/Metop Sodankylä campaign to IASI measurements, Atmos. Meas. Tech., 4, 1177-1189, https://doi.org/10.5194/amt-4-11772011, 2011.

Carbajal Henken, C. K., Diedrich, H., Preusker, R., and Fischer, J.: MERIS full-resolution total column water vapor: Observing horizontal convective rolls, Geophys. Res. Lett., 42, 10074-10081, https://doi.org/10.1002/2015GL066650, 2015.

Chalon, G., Cayla, F., and Diebel, D.: IASI: An Advanced Sounder for Operational Meteorology, Proceedings of the 52nd Congress of IAF, Toulouse France, 1-5 October 2001.

Clough, S. A., Shephard, M. W., Mlawer, E. J., Delamere, J. S., Iacono, M. J., Cady-Pereira, K., Boukabara, S., and Brown, R. D.: Atmospheric radiative transfer modeling: a summary of the AER codes, J. Quant. Spectrosc. Ra., 91, 233-244, 2005.

Dirksen, R. J., Sommer, M., Immler, F. J., Hurst, D. F., Kivi, R., and Vömel, H.: Reference quality upper-air measurements: GRUAN data processing for the Vaisala RS92 radiosonde, Atmos. Meas. Tech., 7, 4463-4490, https://doi.org/10.5194/amt-7-4463-2014, 2014.

GSICS Traceability Statement for IASI and AIRS, available at: $\mathrm{http} / / / \mathrm{www}$.eumetsat.int/website/wcm/idc/idcplg?IdcService= GET_FILE\&dDocName=PDF_TRACE_STAT_IASI_ AIRS\&RevisionSelectionMethod=LatestReleased \&Rendition= Web (last access: 20 June 2017), 2014.

Hewison, T. J., Wu, X., Yu, F., Tahara, Y., Hu, X., Kim, D., and Koenig, M.: GSICS Inter-Calibration of Infrared Channels of Geostationary Imagers using Metop/IASI, IEEE T. Geosci. Remote Sens., 51, 1160-1170, https://doi.org/10.1109/TGRS.2013.2238544, 2013.

Hyland, R. and Wexler, A.: Formulations for the thermodynamic properties of the saturated phases of $\mathrm{H}_{2} \mathrm{O}$ from $173.15 \mathrm{~K}$ to 473.15 K, ASHRAE Tran., 89, 500-519, 1983.

Immler, F. J., Dykema, J., Gardiner, T., Whiteman, D. N., Thorne, P. W., and Vömel, H.: Reference Quality Upper-Air Measurements: guidance for developing GRUAN data products, Atmos. Meas. Tech., 3, 1217-1231, https://doi.org/10.5194/amt-3-1217-2010, 2010 .
Murphy, D. M. and Koop, T.: Review of the vapour pressures of ice and supercooled water for atmospheric applications, Q. J. Roy. Meteor. Soc, 131, 1539-1565, 2005.

Pequignot, E., Blumstein D., and Larigauderie, C.: CNES Technical Note: IASI Noise Covariance Matrix, IA-TN-0000-3271-CNE, 2008.

Pougatchev, N., August, T., Calbet, X., Hultberg, T., Oduleye, O., Schlüssel, P., Stiller, B., Germain, K. St., and Bingham, G.: IASI temperature and water vapor retrievals - error assessment and validation, Atmos. Chem. Phys., 9, 6453-6458, https://doi.org/10.5194/acp-9-6453-2009, 2009.

Reale, A., Sun, B., Tilley, F., and Pettey, M.: The NOAA Products Validation System, J. Atmos. Ocean. Tech., 29, 629-645, https://doi.org/10.1175/JTECH-D-11-00072.1, 2012.

Smith Sr., W. L., Harrison, F., Hinton, D., Miller, J., Bythe, M., Zhou, D., Revercomb, H., Best, F., Huang, H., Knuteson, R., Tobin, D., Velden, C. S., Bingham, G., Huppi, R., Thurgood, A., Zollinger, L., Epslin, R., and Petersen, R.: The Geosynchronous Imaging Fourier Transform Spectrometer (GIFTS) (Invited Presentation), The 11th Conference on Satellite Meteorology and Oceanography (Madison, WI), 2001.

Sommer, M., Dirksen, R., and Immler, F.: RS92 GRUAN Data Product Version 2 (RS92-GDP.2), GRUAN Lead Centre, https://doi.org/10.5676/GRUAN/RS92-GDP.2, 2012.

Tjemkes, S. A., Patterson, T., Rizzi, R., Shephard, M. W., Clough, S. A., Matricardi, M., Haigh, J. D., Hopfner, M., Payan, S., Trotsenko, A., Scott, N., Rayer, P., Taylor, J. P., Clerbaux, C., Strow, L. L., DeSouza-Machado, S., Tobin, D., and Knuteson, R.: The ISSWG line-by-line inter-comparison experiment, J. Quant. Spectrosc. Ra., 77, 433-453, 2003.

Tobin, D. C., Revercomb, H. E., Knuteson, R. O., Lesht, B. M., Strow, L. L., Hannon, S. E., Feltz, W. F., Moy, L. A., Fetzer, E. J., and Cress, T. S.: Atmospheric radiation measurement site atmospheric state best estimates for atmospheric infrared sounder temperature and water vapor retrieval validation, J. Geophys. Res., 111, D09S14, https://doi.org/10.1029/2005JD006146, 2006.

WMO GCOS, Systematic Observation Requirements for SatelliteBASED Data Products for Climate, 154 Document, available at: https://www.wmo.int/pages/prog/gcos/Publications/gcos- 154 . pdf (last access: 8 April 2016), 2011.

WMO GCOS, The GCOS reference upper air network (GRUAN) Manual, Technical Report 170, WMO/WIGOS Technical Report, available at: http://www.wmo.int/pages/prog/gcos/Publications/ gcos-170.pdf (last access: 8 April 2016), 2013a.

WMO GCOS, The GCOS reference upper air network (GRUAN) Guide, Technical Report 171, WMO/WIGOS Technical Report, available at: http://www.wmo.int/pages/prog/gcos/Publications/ gcos-171.pdf(last access: 8 April 2016), 2013b. 